\title{
Chemical Equilibrium and Synergism for Solvent Extraction of Trace Lithium with Thenoyltrifluoroacetone in the Presence of Trioctylphosphine Oxide
}

\author{
Young-Sang Kim, ${ }^{*}$ Gyo In, and Jong-Moon Choi ${ }^{*}$ \\ Department of Atwanced Material Chemistry, Korea Lniversitw, Jochiwon, Choongnam 339-700, Korea \\ ${ }^{\dagger}$ Department of Enironmental Engineering. DongHae Lniveristw, Donghae, Gangw'on 240-712, Korea \\ Received June 14, 2003
}

\begin{abstract}
Equilibria and applications of a synergistic extraction were studied for the determination of a trace lithium by using thenoyltrifluoroacetone (TTA) and triocty lphosphine oxide (TOPO) as ligands. Several equations were derived for the extraction of lithium into m-xylene as a phase of Li-TTA-mTOPO adduct. Distribution coefficients and extraction constant were determined together with a stability constant of the adduct. The adduct was quantitatively extracted from the basic solution of higher than $\mathrm{pH} 9$ by shaking for 30 minutes. $\mathrm{m}$ Xylene was selected as an optimum solvent by comparing the extraction efficiency among several kinds of organic solvents. The stability constant $\left(\beta_{2}\right)$ for Li-TTA/2TOPO was 150 times higher than Li-TTA/TOPO. The distribution coefficient of Li-TTA/2TOPO into $m$-xy lene was 9.12 and the logarithmic extraction constant (log $\mathrm{K}_{\mathrm{ex}}$ ) was 6.76 . Trace lithium of sub-ppm level in seawater samples could be determined under modified conditions and a detection limit equivalent to 3 times standard deviation for background absorption was 0.42 $\mathrm{ng} / \mathrm{mL}$.
\end{abstract}

Key Words : Synergistic solvent extraction, Trace lithium. Thenoyltrifluoroacetone (TTA), Trioctylphosphine oxide (TOPO). Ternary complex

\section{Introduction}

Lithium is being importantly used not only in the industrial factories as an alloying materials. but also in medical and geological fields. ${ }^{1-3}$ An accurate method for the determination of lithium is needed up to trace level. It is directly determined by several instrumental methods such as atonic absorption spectrophotometry. ${ }^{4}$ ion chromatography and so on. An isotope dilution method as the most sensitive technique has been applied to an inorganic mass spectrometry for the determination of ultra trace lithium in biological and environmental samples. ${ }^{1.2}$ Such methods are so significantly affected by sample matrixes that samples of complicated matrix should be pre-treated to separate analytical constituents from the matrix. In addition. a concentration technique is necessary for the analytes of subdetection limit. Various techniques ${ }^{5.6}$ have been applied as a pre-concentration technique together with a solvent extraction.

The extraction is not a continuous procedure and can not be used if the extraction constant is not large. but it has been widely used because the relatively quantitative result can be obtained with its simple procedure. In this work, the solvent extraction technique has been studied to suggest a new method for the separative concentration and determination of trace lithium in a sea water of complicated matrix.

$\beta$-Diketone derivatives were used as ligands for the effective formation of lithium complexes. The $\beta$-diketone forms chelates with various metallic ions and the chelates are extracted into an organic solvent. $\beta$-Diketone has an enol- and keto-forms in a solution by a tautomerism. After a proton is dissociated from enol-form, the anionic group more strongly coordinates with a metal ion to form a complex. The selectivity of reaction to a given element can be improved by substituting $\mathrm{R}_{1}$ and $\mathrm{R}_{2}$ in $\beta$-diketone with other radicals. Acetylacetone is known to form various complexes with about 60 metallic elements. ${ }^{8}$ The acetylacetone is one derivative of $\beta$-diketone in which $R_{1}$ and $R_{2}$ are substituted with two methyl groups.

Sekine and co-ivorkers ${ }^{9.10}$ had studied a synergistic solvent extraction of alkaline earth and alkali metals into $\mathrm{CCl}_{4}$ using benzoyltrifluoroacetone (BFA) together with trioctylphosphine-oxide (TOPO) and tetrabutylammonium ion $\left(\mathrm{TBA}^{-}\right)$. in which BFA and TOPO were main and auxiliary ligands respectively and $\mathrm{TBA}^{-}$was used as a counter ion of ion pair. Noro and others ${ }^{11}$ reported that europium was extracted into $\mathrm{CCl}_{4}$ by a synergistic extraction using BFA and $\mathrm{TBA}^{-}$

Using various derivatives of benzoylpyrazolone. Mukai and others ${ }^{12}$ compared the extraction efficiency according to the type of derivatives and solvent for the extraction of alkali and alkaline earth elements. And also they optimized the experimental conditions and obtained extraction constants for the extraction of rare earth elements with benzoylpyrazolone derivative and TOPO. ${ }^{13}$ Umetani et al. synergistically extracted alkaline earth metals into benzene and cyclohexane using benzoylpyrazolone derivative and $\mathrm{TOPO}^{14}$ and zinc into cyclohexane with benzoylpyrazolone derivative and perchloric acid. ${ }^{15}$ In addition, the effects of structure of the neutral ligands were investigated on synergistic extraction of analytes with benzoylpyrazolone derivatives and various neutral ligands. ${ }^{\text {li..17 }}$

On the other hand. Olmiya and co-workers ${ }^{18}$ reported the experimental results for synergistic extraction of silver ion in aqueous solution into chloroform with $\mathrm{TBA}^{+}$as well as 


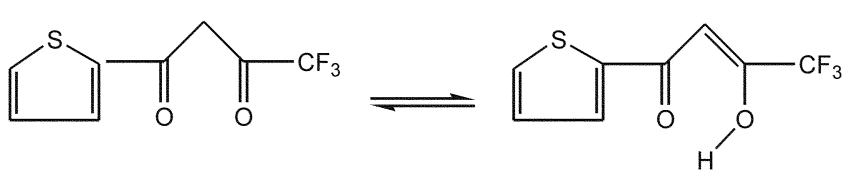

Figure 1. Structure of thenoyltritluoroacetone.

isopropyltropolone. Sekin et $a .^{19}$ extracted six elements of copper, nickel, zinc and so on into chloroform with isopropyltropolone and TOPO.

Thenoyltrifluoroacetone (TTA) was used as a chelating agent in this work. It was one of $\beta$-diketone derivatives in which $R_{1}$ and $R_{2}$ were substituted with 2-thenoyl and $C F_{3}$. The acidity of enol-form increased by the influence of $-\mathrm{CF}_{3}$.

Since Calvin and Wilson firstly synthesized TTA in 1944, it has been widely used as a chelating agent for the determination of neptunium and plutonium and the extraction of lanthanides and actinides. ${ }^{7.8}$ As in case of other $\beta$-diketone derivatives. TTA was known to have a synergism to improve the extraction of metal ions as forms of adduct or ion pair with TOPO or $\mathrm{TBA}^{+}$. Noro and co-workers ${ }^{20,21}$ have investigated the composition of extracting species and obtained equilibrium constants and distribution coefficients in the synergistic extraction of five rare earths and lanthanides by using TTA and $\mathrm{TBA}^{+}$. Sekine of al ${ }^{22-25}$ have performed some studies on extraction of several elements into solvent using TTA and TOPO or TBA ${ }^{-}$. Recently, Sekine and Hokura ${ }^{26.27}$ also reported a research paper on the measurement of reaction rate for the formation of metal adduct complexes of TTA and TOPO. On the other hand. Takazawa of $a l^{28}$ measured enthalpy changes for each process to examine closely a synergism in such extraction from a thermodynamic view point. And Jaffe and coworkers ${ }^{29}$ have studied the complex formation mechanism, equilibrium constants and reaction rate constants for the solvent extraction of nickel, copper, cobalt and iron with TTA. Besides. Machida et $a l{ }^{70}$ have investigated the dependencies of the type of organic solvent for synergistic extraction of lithium using $\mathrm{T}$ "]A and $\mathrm{TOP}^{2} \mathrm{O}$.

As mentioned above, many researches have been reported for the extraction conditions, efficiencies and stabilities of metal complexes, but there were not so many examples to use $\beta$-diketone derivatives for the extraction of lithium. Only comparison of extraction efficiency has been investigated by obtaining distribution ratio. In this work, basic researches for the aquisition of distribution ratio and extraction constant as well as the optimization of extraction conditions have been tried to extract trace lithium in sample solutions of complicated matrixes. And a proper procedure was established to determine trace lithium in sea water samples.

\section{Experimental Section}

Reagents and Instruments. All reagents were of analytical grade and a deionized water purified by Millipore Milli$Q$ system was used in this experiment. The standard solution of lithium was prepared by diluting $1,000 \mu \mathrm{g} / \mathrm{mL}$ Li SRM (Standard Reference Material) solution of NIS' (National
Institute of Standards and Technology). Thenoyltrifluoroacetone (TTA, Aldrich Co.) and trioctylphosphine-oxide (TOPO, Aldrich $\mathrm{Co}$.) were dissolved in $m$-xylene (Junsei Co., Japan) for uses.

Flame-AAS (model 2380, Perkin-IImer Co.) equipped with a premixed nebulizer was used to measure absorbances of lithium for its distribution ratio and extraction constants. Airacetylene was used as a flame gas. The concentration of lithium in real sea water samples was obtained by measuring the absorbances with GF-AAS. The absorbances of chemical species in extraction solutions were measured by UV/Vis spectrophotometer (Cary $1 \Gamma$, Varian $C o$.) and $1.0 \mathrm{~cm}$ quart?. cell was used. The $\mathrm{pH}$ was measured with Fyela $\mathrm{pH}$ meter (PHM-2000, Tokyo Rikakikai Co.) and Ingold glass electrode was used after adjusted with buffer solutions.

Experimental Procedure. The $\mathrm{pH}$ in $0.1 \mathrm{M}$ ammonium chloride solution of $5.76 \times 10^{-4} \mathrm{M}$ lithium solution was adjusted to 9.0 with ammonia water. After $25.00 \mathrm{~mL}$. of this solution was taken in a $250 \mathrm{ml}$, separatory funnel, $25.00 \mathrm{ml}$. $m$-xylene solution of TTA and TOPO was added and the solution was shaken for 30 minutes by a reciprocal shaker. It was stood for 30 minutes for the phase separation. I. ithium remained in an aqueous solution was determined by flame AAS to calculate the distribution ratio of lithium and to specify existent species at each extraction step. And the equilibrium concentration of TTA was determined by a potentiometric titration in an aqueous solution of $0.10 \mathrm{M}$ $\mathrm{HCl}$. The equilibrium concentration of TOPO and the extraction constant was calculated with derived equations.

In order to obtain reproducibility and recoveries for the determination of trace lithium in diluted sea water, $1.38 \mathrm{~g}$ of ammonium dihydrogen phosphate and $2.5 \mathrm{~mL}$, of concentrated ammonia water were added into $100 \mathrm{ml}$ of seawater sample to form the phosphate precipitates of calcium and magnesium. The precipitates were removed by filtration. And the $\mathrm{pH}$ of the sample solution was adjusted to 8.0 with ammonia water or hydrochloric acid. A $10.0 \mathrm{ml}$ of $\mathrm{m}$ xylene solution of $0.1 \mathrm{M}$ TTA and $0.05 \mathrm{M}$ TOPO was added to this solution in a separatory funnel and the solution was vigorously shaken by a mechanical shaker for 20 minutes. The organic phase was separated from the aqueous solution after standing for 20 minutes. And $20 \mu \mathrm{L}$ of this $m$-xylene solution was injected into a graphite tube to measure the absorbance by GF-AAS.

\section{Results and Discussion}

Type of Solvent. The selection of the best solvent is very important to stabilize lithium species and improve the efficiency for the solvent extraction of lithium from an aqueous solution. Such selection should be done before the optimization of other experimental conditions. In this work. the extraction efficiencies were compared each other for five kinds of solvents such as chloroform, methyl-isobutylketone (MIBK), n-hexane, $m$-xylene, and benzene. The absorbance of lithium stripped after the extraction was measured in an aqueous solution for this comparison. As shown in Figure 2. 


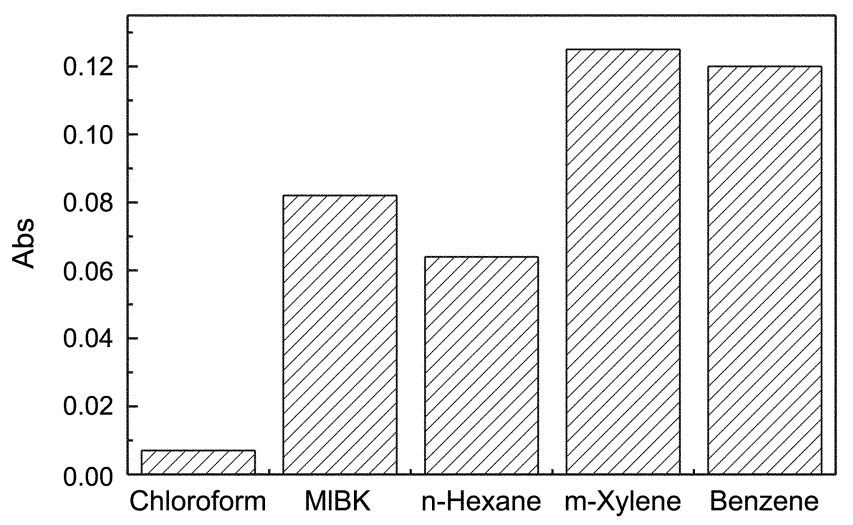

Figure 2. Litraction efficiency as an absorbance according to the type of solvent.

benzene and $m$-xylene provided much higher absorbances than other solvents. This result was somewhat different to Machida's experiment ${ }^{30}$ which reported that an aliphatic hydrocarbon would show higher efficiencies than aromatic solvents by measuring the interfacial tension between aqueous and organic phases. His system was very similar to ours. That is, lithium was extracted as the adduct complex of TTA and TOPO.

Becaluse lithium ion could form the nonpolar compound of high molecular weight with TTA and TOPO, nonpolar solvents showed the excellent efficiencies compared to other polar solvents. On the other hand, it is well known that MIBK has been widely used as a solvent in the solvent extraction and sublation because of high efficiency in the extraction and low background in the atomic absorbance measurement. But MIBK was a little polar as well as soluble in an aqueous solution. From the consideration of such phenomena, $m$-xylene was selected as a proper solvent in this synergistic extraction.

Effect of $\mathbf{p H}$. After the $\mathrm{pH}$ in $0.1 \mathrm{M}$ ammonium chloride solution of $5.76 \times 10^{-4} \mathrm{M}$ lithium was varied from 6.0 to 9.0 with hydrochloric acid and ammonia water, the lithium was

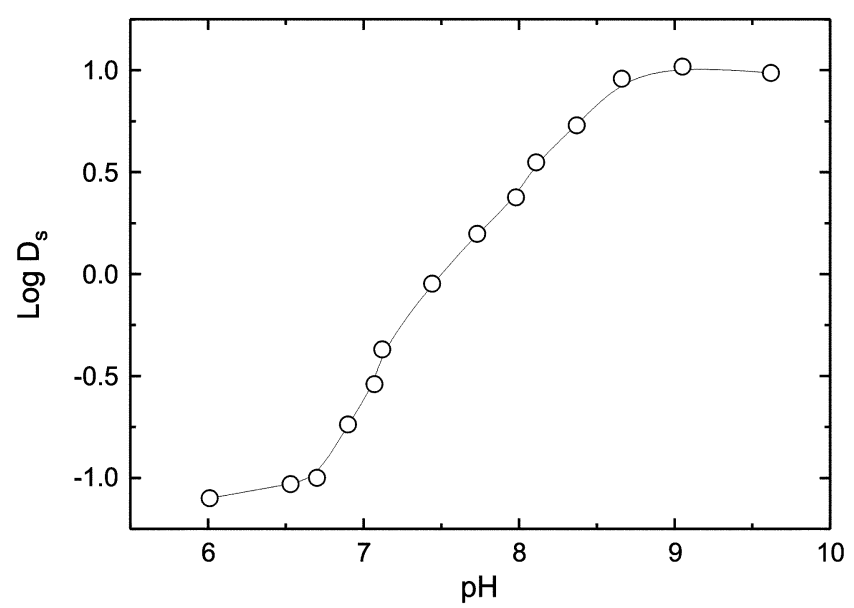

Figure 3. Logarithmic distribution ratio $(\log D s)$ of lithium between aqueous solution and $m$-xylene as a function of equilibrium pll in the aqueous phase. extracted into $m$-xylene solution of $0.01 \mathrm{M}$ TTA and $0.01 \mathrm{M}$ TOPO as an adduct complex. The amount of extracted lithium was calculated by measuring the atomic absorbance of lithium remained in an aqueous solution. The distribution ratio for lithium species were obtained from these extracted and remained amounts at different $\mathrm{pH}$ (see Fig. 3). The constant ratio was shown at $\mathrm{pH}$ higher than 9.0 , but lithium was nearly not extracted in acidic solution of $\mathrm{pH}$ less than 7.0 .

And also the constant extraction efficiency was shown in the $\mathrm{pH}$ of higher than $8.0 .^{31}$ This was considered to be because the volume of aqueous solution was more than 10 times of organic phase. This phenomenon could be due to the increase of absolute amount of $\mathrm{OH}^{-}$in a large volume of aqueous solution. And this was different with previous results ${ }^{10,19,22}$ about the extraction of lanthanides and heavy metals using TTA and TOPO, in which the extraction efficiencies were high in the acidic solution of low $\mathrm{pH}$. L ithium has not so strong coordination power with TTA compared to other polyvalent ions that TTA should be presented as enolform to make enolate complex with lithium. But the enolate ion can be formed from enol-form in a basic solution and much distributed to the aqueous solution. The enolate ion more strongly forms adduct complexes with lithium ion and TOPO. From this result, $\mathrm{pH}$ of solution was adjusted 8-9 with ammonia water. The solution was buffered by $0.1 \mathrm{M}$ ammonium chloride in aqueous solution. But because there were some ions in a sea water which provide the buffer action, ${ }^{3]}$ real analytical samples might not be buffered.

Extraction Fquilibria. As in above description, HTTA in $m$-xylene is distributed to a basic acpueous solution as a TTA ${ }^{-}$ to form Li-TTA/TOPO adduct complex together with TOPO. And the adduct is back-extracted to the $m$-xylene as following equations:

$$
\begin{aligned}
& (\mathrm{HTTA})_{i r g}-\left(\mathrm{TTA}^{-}\right)_{c k q}+\left(\mathrm{H}^{-}\right)_{c k t} \\
& \mathrm{Li}^{-}-n \mathrm{TTA}^{-}+m \mathrm{TOPO}_{n \mathrm{x}}-\left[\mathrm{Li}(\mathrm{TTA})_{t s}(\mathrm{TOPO})_{m}\right]_{u x y}
\end{aligned}
$$

An extraction constant for eq. (1) can be expressed as a follow:

$$
K_{\mathrm{eX}}-\frac{\left[\mathrm{Li}(\mathrm{TTA})_{n} \cdot\left(\mathrm{TOPO}_{m}\right]_{\mathrm{mg}}\right.}{\left[\mathrm{Li} \mathrm{i}^{\prime}\right][\mathrm{TTA}]^{n}[\mathrm{TOPO}]_{\mathrm{org}}^{m}}
$$

The equation is simplified using distribution ratio.

where,

$$
\begin{aligned}
& K_{\mathrm{cx}}=\frac{D_{\mathrm{s}}}{\left[\mathrm{T}^{\mathrm{T}} \mathrm{TA}^{-}\right]^{\prime \prime}\left[\mathrm{TO}^{2} \mathrm{O}\right]_{\mathrm{org}}^{\mathrm{th}}} \\
& D_{s}-\frac{\left[\operatorname{li}(\mathrm{TTA})_{n} \cdot(\mathrm{TOPO})_{m}\right]_{G \mathrm{H}}}{\left|\mathrm{Li}^{\prime}\right|}
\end{aligned}
$$

If both sides of eq. (3) are expressed by logarithm.

$$
\log K_{\mathrm{ex}}-\log D_{\mathrm{s}}-n \log \mid \mathrm{TT} \Lambda \mathrm{I}-m \log \text { TOPO|}\left.\right|_{\text {orm }}
$$

In this equation, $\log D_{\mathrm{s}}$ depends on $\left.\log \left[\mathrm{I}^{\mathrm{I}}\right] \mathrm{A}^{-}\right]$at the constant concentration of $1 \mathrm{OPO}$ because $K_{\mathrm{x}}$ is a constant. The relation can be expressed as the equation, $\mathrm{Y}=n \mathrm{X}+\mathrm{A}$. 

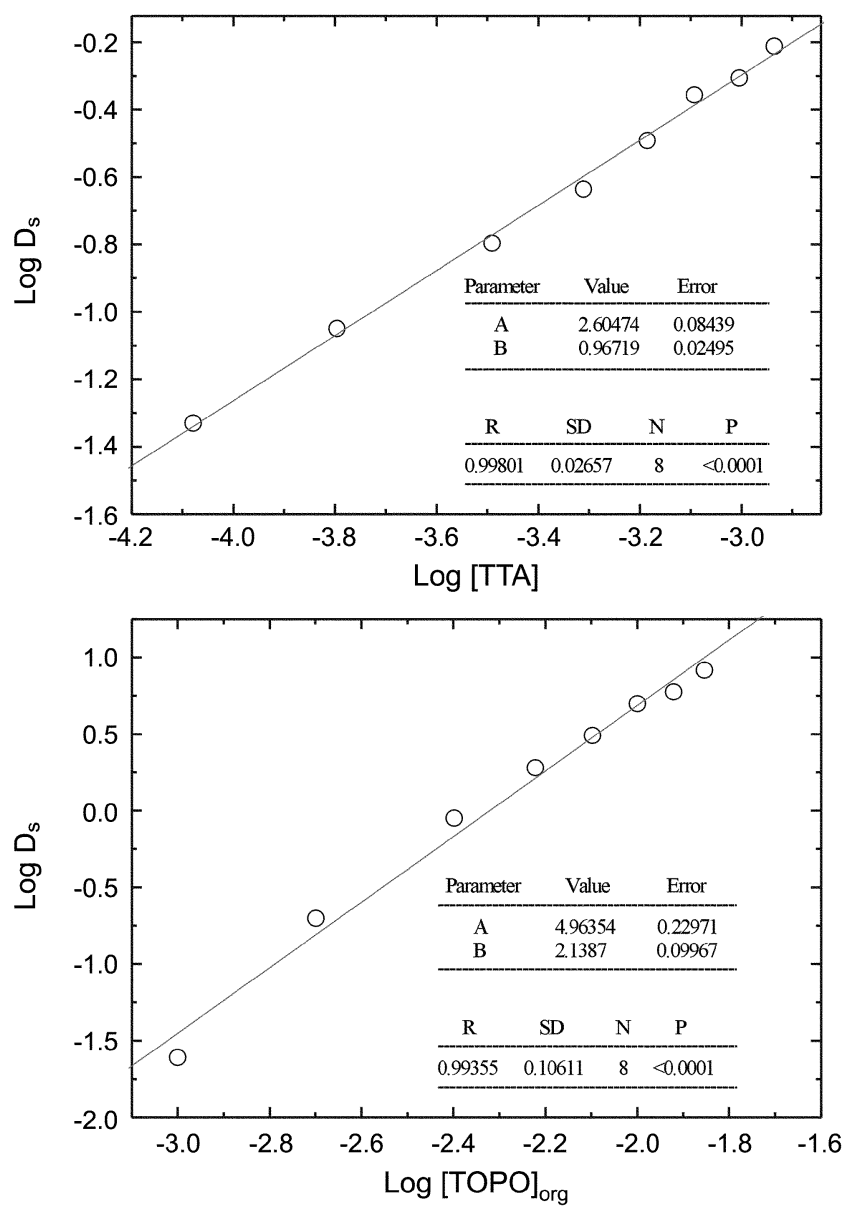

Figure 4. Plots of logarithmic distribution ratio (log Dsj versus log ['IAA-1 and log ['OOPO] al equilibritum.

Thus, when $\log D_{\mathrm{s}}$ is plotted versus $\log \left[\mathrm{TTA}^{-}\right]$, the curve should be linear and the slope, $n$, becomes the mole number of TTA to combine with one mole of $\mathrm{li}^{+}$.

The $\mathrm{pH}$ was 9.0 in an aqueous solution. the concentration of $\mathrm{JOPO}$ in $m$-xylene was fixed with $0.01 \mathrm{M}$ and the concentration of $\left[\mathrm{TA}^{-}\right.$was varied from $1.0 \times 10^{-4}$ to $1.4 \times 10^{-3}$ $M$. The distribution ratios were calculated at given concentrations of $\mathrm{ITAA}^{-}$by measuring the remained concentration of $\mathrm{Li}^{\prime}$ in the aqueous solution and the logarithmic values were plotted against the logarithmic concentrations of I"IA (see Fig. 4). The curve was linear with the slope of 0.97 . It meant that $n$ in eq. (4) was 1 . That is, LilllA complex of I to 1 was formed under these conditions. But because Lil"lA m m IOPO was only adduct complex of variable [OPO, it was difficult to derive such a relationship and to obtain exact $m$ value as in the case of ["IA.

Besides, a stability constant $(\beta)$ for the adduct complex was introduced to describe the stoichiometry in detail. Overall reaction for the stability constant $(\beta)$ can be written as follows:

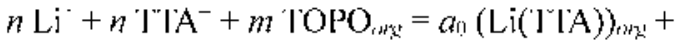

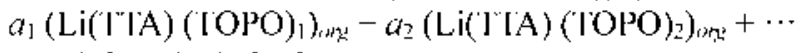

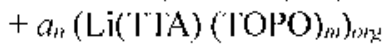

where, $n-\sum_{k=0} a_{k}$ and it $m-\sum_{k} k \cdot a_{k}$

The distribution ratio can be changed as following equation using eq. (5):

$D_{s}=$

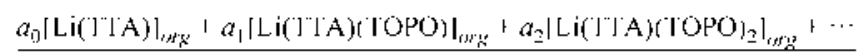

$$
\left[\mathrm{Li}^{+}\right]
$$

And equation (6) can be simplified as follows:

$$
D_{1}=D \cdot\left(a_{0}+a_{1} \beta_{1}[\mathrm{TOPO}]_{\text {ryxt }}+a_{2} \beta_{2}[\mathrm{TOPO}]_{m+2}^{2}+\cdots\right)
$$

where, $D-\frac{|\operatorname{Li}(\mathrm{TTA})|_{0, r y}}{\left[\mathrm{Li}^{1}\right]}$ and

$$
\beta_{m}-\frac{\left[\mathrm{Li}(\mathrm{TTA})(\mathrm{TOPO})_{m}\right]_{a r s}}{[\operatorname{Li}(\mathrm{TT} \Lambda)]_{m, g} \cdot[\mathrm{TOPO}]_{m, r s}^{m}}
$$

The equation (7) can be indicated as a polynomial expression of $\mathrm{Y}=\mathrm{A}+\mathrm{B} \cdot \mathrm{X}-\mathrm{C} \cdot \mathrm{X}^{2}+\cdots$. The $\mathrm{pH}$ of aqueous solution was adjusted to 9.0 and the concentration of TTA $^{-}$was fixed at $0.01 \mathrm{M}$ in $m$-xylene. After species of lithium were extracted, the distribution ratios were plotted against the concentration of TOPO from $1.0 \times 10^{-3}$ to $1.4 \times 10^{-2} \mathrm{M}$ at a fixed concentration range of TTA (see Fig. 5). The figure was a curve-fitting result of the quadratic ecuation.

From the curve-fitting result, $a_{2} \beta_{2}$ was known to be about 150 times of $a_{1} \beta_{1}$. In the extraction of lithium using TTA and TOPO, lithium was nearly not extracted as forms of $\mathrm{I}$.i(TTA) and $\mathrm{l}$.j(TTA) (TOPO). But li(TTA).(TOPO) 2 was more stable than $\mathrm{L}$ (TTA) (TOPO) so that most of lithium was extracted into $m$-xylene as a form of li(TTA) (TOPO). Therefore, the equation (5) could be simplitied as follow:

$$
\mathrm{Li}^{\prime}-\mathrm{TTA}^{-}-2 \mathrm{TOPO}_{\text {rorg }}-\left\{\mathrm{Li}(\mathrm{TTA}) \cdot\left(\mathrm{TOPO}_{2}\right\}_{\text {ary }}(8)\right.
$$

And the formation procedure could be given as following scheme:

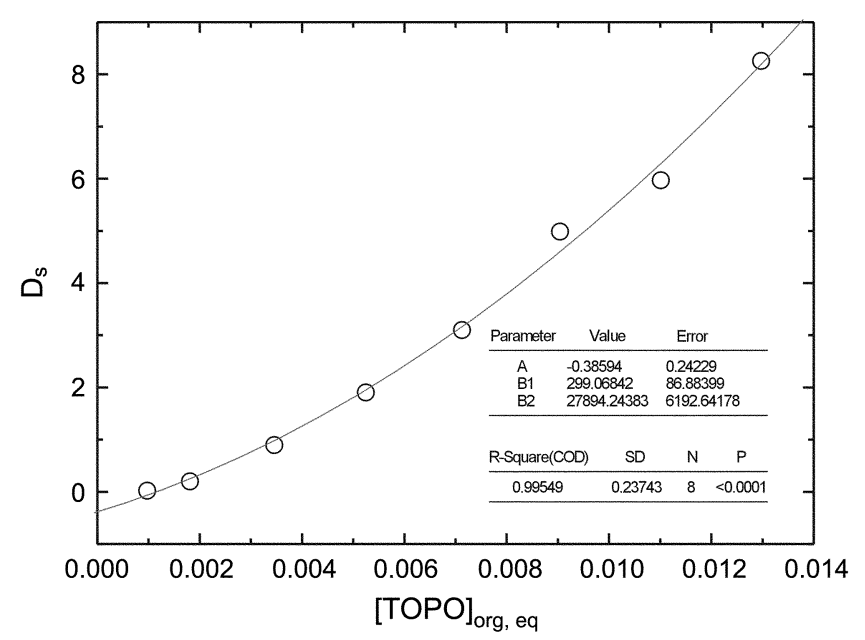

Figure 5. Plot of distribution ratio ( $\left.\log D_{s}\right)$ against molar concentration of ' $\mathrm{TOPO}$ at equilibrium. 


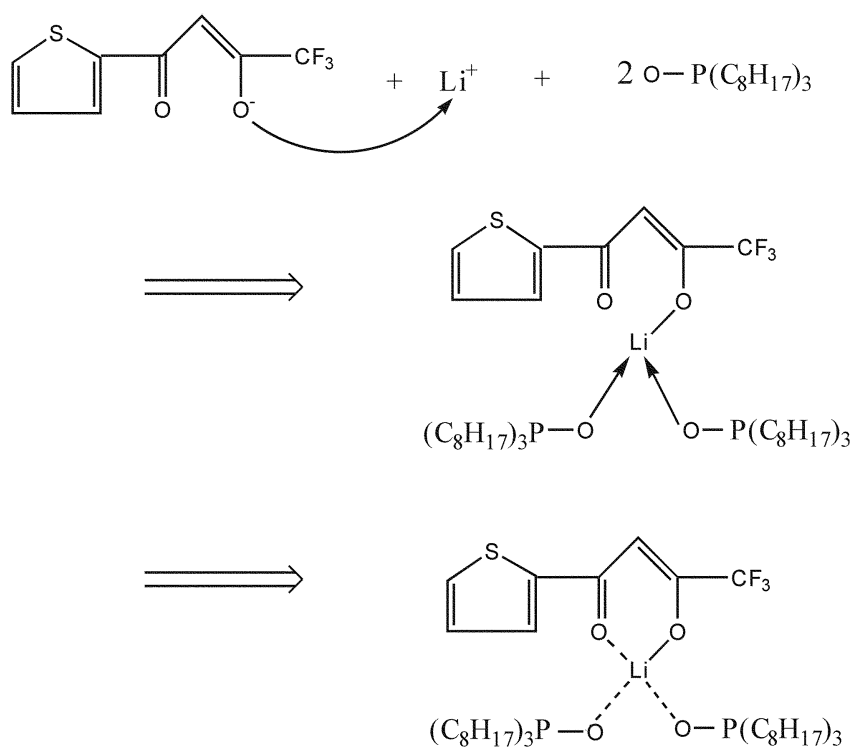

Extraction Constant. The extraction constant. $K_{\mathrm{cx}}$, can be expressed with the equilibrium constant for eq. (8) as follows:

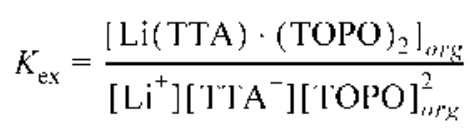

If eq. (9) is simplified.

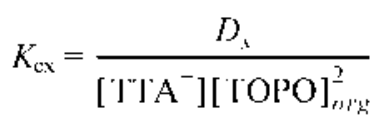

where, $D_{s}=\frac{\mid \mathrm{Li}(\mathrm{TTA}) \cdot\left(\mathrm{TOPO}_{2} \mathrm{I}_{t \prime \prime g}\right.}{\left[\mathrm{Li}^{-}\right]}$.

Both sides of eq. ( 10$)$ are expressed with logarithm.

$$
\log K_{\mathrm{Lx}}-\log D_{\mathrm{s}}-\log \left[\mathrm{TTA}^{-}\right]-2 \log [\text { TOPO }]_{\mathrm{rmr}}
$$

The extraction constant, $K_{\mathrm{ex}}$, was calculated by obtaining distribution ratio under experimental conditions at given concentrations of TTA and TOPO. $\log K_{\mathrm{L}}$ values were listed in Table 1 together with other data and the average was 6.75 .

Reproducibility and Recoveries. Based on above considerations, a proper procedure was prepared for the separative concentration and determination of trace lithium in diluted sea water samples.

Many kinds of ions were dissolved in sea water at the variable levels of concentration ${ }^{31}$ so that their interferences were investigated in the extraction of lithium by given method. Alkaline metal ions like $\mathrm{Na}^{-}$and $\mathrm{K}^{+}$did nearly not interfere the extraction, but the interferences of alkali earth metals such as $\mathrm{Ca}^{2-}$ and $\mathrm{Mg}^{2-}$ were serious because their charge densities were similar to lithium ion. ${ }^{+}$The interferences were successfully eliminated by filtering out their precipitates with $\mathrm{NH}_{4} \mathrm{H}_{2} \mathrm{PO}_{4}$. And then lithium was determined by GF-AAS after the extraction of it with $m$-xylene solution of $0.1 \mathrm{M}$ TTA and $0.05 \mathrm{M}$ TOPO. For this, a calibration curve was prepared with a series of standard

\begin{tabular}{|c|c|c|c|}
\hline$\left[\mathrm{IIA}^{-}\right]$ & [10PO & $D_{s}$ & $\log K_{i, \mathrm{r}}$ \\
\hline $8.338 \times 10^{5}$ & $9.95 \times 10^{3}$ & 0.04678 & 6.75 \\
\hline $1.600 \times 10^{+}$ & $9.91 \times 10^{3}$ & 0.08936 & 6.76 \\
\hline $3.212 \times 10^{4}$ & $9.84 \times 10^{3}$ & 0.16014 & 6.71 \\
\hline $4.889 \times 10^{+}$ & $9.78 \times 10^{3}$ & 0.23126 & 6.69 \\
\hline $6.521 \times 10^{+}$ & $9.72 \times 10^{3}$ & 0.32247 & 6.72 \\
\hline $8.079 \times 10^{+}$ & $9.65 \times 10^{3}$ & 0.44108 & 6.77 \\
\hline $9.898 \times 10^{+}$ & $9.62 \times 10^{3}$ & 0.49471 & 6.73 \\
\hline $1.160 \times 10^{3}$ & $9.56 \times 10^{3}$ & 0.61487 & 6.76 \\
\hline $9.72 \cdot 10^{3}$ & $9.723-10^{4}$ & 0.02462 & 6.43 \\
\hline $9.64 \cdot 10^{3}$ & $1.81 \times 10^{3}$ & 0.19867 & 6.80 \\
\hline $9.46 \cdot 10^{3}$ & $3.46 \times 10^{3}$ & 0.89674 & 6.89 \\
\hline $9.36 \cdot 10^{3}$ & $5.24 \times 10^{3}$ & 1.90547 & 6.87 \\
\hline $9.30 \cdot 10^{3}$ & $7.13 \times 10^{3}$ & 3.10171 & 6.82 \\
\hline $9.26 \cdot 10^{3}$ & $9.04 \times 10^{3}$ & 4,98659 & 6.82 \\
\hline $9.24 \cdot 10^{3}$ & $1.101-10^{-}$ & 5,97254 & 6.73 \\
\hline $9.22 \cdot 10^{3}$ & $1.297 / 10^{2}$ & 8.25971 & 6.73 \\
\hline
\end{tabular}

Table 1. Solvent extraction data and extraction constants at equilibrium

Table 2. Analytical results of analyte in real sample by proposed method

\begin{tabular}{ccccc}
\hline Sample & $\begin{array}{c}\text { I.jadded } \\
\text { ngiml }\end{array}$ & $\begin{array}{c}\text { I.i lound } \\
\text { ng/mI }\end{array}$ & $\begin{array}{c}\text { RSI) } \\
\%\end{array}$ & $\begin{array}{c}\text { Recovery } \\
\%\end{array}$ \\
\hline Tac-jong-dac & 0.00 & 20.09 & 1.89 & \\
& 20.00 & 39.61 & & 97.6 \\
Choo-am & 0.00 & 17.26 & 1.56 & \\
Muk-ho & 20.00 & 38.26 & & 105.1 \\
[ll-jiu & 0.00 & 14.88 & 1.61 & \\
Dac-chon & 0.00 & 21.08 & 1.80 & \\
\hline
\end{tabular}

*Number of analyses: $n-5$

solutions which were made in a synthetic sea water. The linearity of curve was 0.9953 and the detection limit equivalent to three times standard deviation for background was $0.42 \mathrm{ng} / \mathrm{mL}$. Sea water samples were ten times diluted with the synthetic sea water for this purpose. As in lable 2 , the recoveries for the reliability of this method were obtained with $94-106 \%$ in spiked real samples in which 20 $\mathrm{ng} / \mathrm{mL}$ lithium was added and the reproducible results were obtained with RSD of less than $2.0 \%$. In sumınary, this procedure was expected to be useful in the determination of trace lithium in various samples such as experimental samples and industrial materials.

\section{References}

1. Sun, X. Г.: Ting. B. T. G.: 7.ciscl, S. II, Janghobani, M, Analist 1987. $I / 2.1223$.

2. Park. C.. I. Inats'st 1996. 121. 1311.

3. Greentwood. N. N.: Earnshaw. A. Chemisty of the Element. Ist Ed:: Pergamom Press Inc.: USA. 1984: pp 76-77,

4. Bernhard. W. Atomic Absorption Spectometry. 2nd Ed.: VCH: USA. 1976: рр 295-296.

5. Fodor. P.: Barnes. R. M. Spectrochin feta 1980. /19.67.

6. Kin. Y. S.: Choi. I. M.: Park. S. I. Anat Sci \& Tech 1989. 2. 13 
7. Kolthoff. I. M.: Elving. P. J. Thaties on Anahtical Chemistry 2nd Ed.: John Wiley Sons: U.S.A. 1983: Vol. 3. p 478.

8. Jeffery, G. H.: Bassett. J.: Mendhm. J.: Denny. R. C. Toget's Textbook of Quantitative Chentical Anolysis. 5th Ed.: Longman: England, U.K.. 1989: pp 169-170.

9. Sekin. T.: Takaki, K. Bull Chem. Soc. Jph. 1993. 66, 2558.

10. Sekin. T.: Thi Kim Dung. N. Anal. Sci. 1993. 9.851.

11. Noro. J.: Sekin. T. Bull Chem. Soc. Jpn. 1992. 65. 1910.

12. Mukai. H.: Miyazaki. S.: Unetani. S.: Kihara. S.: Matsui. M. Anat Chim Acta 1989.220.111.

13. Mukai, H: Unnetani, S.: Matsui. M. Anal. Sci. 1997. 13 (sup). 145.

14. Umetani, S.: Sasayama. K: Matsui, M. Anal Chim. Acta 1982. 134,327 .

15. Umetani. S.: Matsui. M. Bull. Chent. Soc. Jpn. 1983. 56. 3426.

16. Umetani. S.: Kihara. S.: Matsui. M. Anot Chim. Acta 1990. 232. 293.

17. Umetani, S: Matsui, M. Anal Chem. 1992. 64, 2288

18. Onmiva, Y.: Sekin. T. Anal. Sci. 1996, 12, 249.

19. Sekin. T.: Minovama, I.: Tebakari, M.: Noro, J. Buhl chem. Soc. Jpn. 1997. 70. 1385 .
20. Noro, J; Sekin, T. Bull. Chem. Soc. Jpn. 1992. 65, 2729

21. Noro. J.: Sekin. I. Bull. Chent. Soc. Jpn. 1993.66. 450.

22. Sekint. T.: Dyrssen. D. Anal Chint . Acta 1967.37.217.

23. Sekin1. T.: Takahashi. Y.: Ihara. N. Bull. Chem. Soc. Jpn. 1973. t6. 388.

24. Sekin. T.; Saitou, T. Bull. Chem. Soc. Jph 1983. 56. 700.

25. Sekin. T; Thi Kim Dung. N.: Noro. J. Bull. Chem. Soc. Jpn. 1994. 67.432 .

26. Sekin1. T.: Hokura. A.: Tanakia. I. Anal. Sci. 1996. 12.747.

27. Hokura. A.: Sekin. T. Anal. Sci. 1997. 13. 19.

28. Takazawa, Y; Itabashi. H; Kawamoto, H. Anal Sci. 1996, 12. 985.

29. Marvin. R. J.: Douglas, P. F; Michael. C.; Norman, S. J. Am Chent Soc. 1971. 16.2878.

30. Machida. I.: Shibata. T.: Nishimura. S. Techologv Reports of Kamsai Lhin: Kansai. Jprn.. 1979: No. 20. March. p 61.

31. Kim, Y. S.: In. G; Choi, J. M.; Lee. C. W. Bull Koman Chem. Soc. $2000,21,855$.

32. Segar. D. A. Introdiction to Ocean Sciences. Wadsworth: Belmont, U.S.A. 1998: pp 1 16-1 19. 